\title{
Polymerization of Methacrylamide Initiated by Potassium Permanganate/Glycollic Acid Redox System
}

\author{
K. C. GUPTA and K. BEHARI* \\ Department of Chemical Engineering, I.I.T. Delhi-16, India \\ * Department of Chemistry, University of Allahabad, Allahabad-2, India
}

(Received September 1, 1986)

\begin{abstract}
The kinetics of potassium permanganate/glycollic acid redox pair initiated polymerization of methacrylamide has been investigated under nitrogen atmosphere at $35 \pm 1^{\circ} \mathrm{C}$. The rate of polymerization with respect to methacrylamide shows square dependence and the order with respect to potassium permanganate has been found to be half. The initial rate of polymerization is almost independent of the concentration of glycollic acid but the maximum conversion shows a decreasing trend. Variation in $\mathrm{pH}$ during the change in the concentration of glycollic acid has also been found to be an important factor in controlling the rate of polymerization. The overall energy of activation $\Delta E$ has been found to be $73 \pm 2 \mathrm{~kJ} \mathrm{~mol}^{-1}$. The viscometric average molecular weight increases in proportional to increase in the concentration of methacrylamide and decreases inversely to the square root concentration of permanganate. On the basis of experimental results a tentative mechanism has been proposed.

KEY WORDS Kinetics / Polymerization / Methacrylamide / Glycollic Acid / Intrinsic Viscosity / Reaction Scheme /
\end{abstract}

Hydroxy acids in combination with various oxidents form an efficient redox pair to initiate vinyl polymerization processes. Some papers describe the kinetic study of vinyl monomers in the presence of permanganate ${ }^{1,2}$ and hydroxy acids but it is of interest to note that no author has derived a suitable mechanism to explain the experimental results. Therefore, in the present communication, an effort has been made to explain the results by proposing a suitable mechanism based on the experimental findings.

\section{EXPERIMENTAL}

Methacrylamide (E. Merck) was purified by recrystallization from 4:1 mixture of benzene-alcohol and dried over anhydrous silica gel $\left(\mathrm{mp} 109.6^{\circ} \mathrm{C}\right)$. The solution of glycollic acid (E. Merck) and permanganate was prepared in triply distilled water. The rate of monomer disappearance was determined bromometrically. ${ }^{3}$ Polymethacrylamide samples collected under different kinetic conditions were dissolved in a $0.05 \mathrm{M}$ aqueous magnesium perchlorate to determine the intrinsic viscosity using the Ubbelohde type viscometer at $25^{\circ} \mathrm{C}$. The viscometric average molecular weight $\left(\bar{M}_{v}\right)$ was calculated using the equation given by Chatterjee et al. ${ }^{4}$

$$
[\eta]_{25^{\circ} \mathrm{C}}=3.28 \times 10^{-4} \bar{M}_{v}^{0.55}
$$

\section{RESULTS AND DISCUSSION}

The addition of permanganate to a solution of methacrylamide produced instantaneously a brownish black homogeneous solution of hydrated manganese dioxide which in presence of glycollic acid produced $\mathrm{Mn}$ (III) as suggested by Tompkin et al. ${ }^{5}$ Manganese(III) ions are very reactive and make complexes 
with glycollate ions and hydroxyl ions. The Mn(III) hydroxyl ion complex associates with the monomer molecules as suggested by Gopalan et al. ${ }^{6}$ The initiation process can be presumed due to the interaction of complexes of $\mathrm{Mn}$ (III) formed with monomer and glycollic acid. Therefore, on the basis of experimental findings, the following probable reaction steps are proposed.

$$
\begin{aligned}
& \text { 3> } \mathrm{C}=\mathrm{C}_{-}-2 \mathrm{MnO}_{4}^{-}+(4+x) \mathrm{H}_{2} \mathrm{O} \\
& \stackrel{\text { Fast }}{\longrightarrow} 2 \mathrm{MnO}_{2} \cdot x \mathrm{H}_{2} \mathrm{O}+3-\underset{C_{1}}{\mathrm{OH}} \stackrel{\mathrm{O}}{\mathrm{C}}-\mathrm{P}_{-}+2 \mathrm{OH}^{-} \\
& \mathrm{Mn}(\mathrm{IV})+\mathrm{H}_{2} \mathrm{O} \frac{k_{1} \text { slow }}{\text { (acidic medium) }} \\
& \mathrm{Mn}(\mathrm{III})+\dot{\mathrm{OH}}+\mathrm{H}^{+} \\
& \mathrm{Mn}(\mathrm{III})+2 \mathrm{CH}_{2} \mathrm{OHCOO}^{-} \underset{\text { Fast }}{\stackrel{k_{2}}{\longrightarrow}} \\
& \mathrm{Mn}\left(\mathrm{CH}_{2} \mathrm{OHCOO}\right)_{2}^{+} \\
& \mathrm{Mn}(\mathrm{III})+\mathrm{H}_{2} \mathrm{O} \stackrel{k_{\mathrm{h}}}{\rightleftharpoons} \mathrm{Mn}(\mathrm{OH})^{2+}+\mathrm{H}^{+} \\
& \mathrm{Mn}(\mathrm{OH})^{2+}+\mathrm{M} \underset{\text { Slow }}{\stackrel{k_{3}}{\longrightarrow}}(\mathrm{Mn}(\mathrm{OH})(\mathrm{M}))^{2+} \\
& (\mathrm{Mn}(\mathrm{OH})(\mathrm{M}))^{2+}+\mathrm{M} \underset{\text { Slow }}{\stackrel{k_{4}}{\longrightarrow}}\left(\mathrm{Mn}(\mathrm{OH})(\mathrm{M})_{2}\right)^{2+}
\end{aligned}
$$

$$
\begin{aligned}
\left(\mathrm{Mn}(\mathrm{OH})(\mathrm{M})_{2}\right)^{2+}+ \\
\left(\mathrm{Mn}\left(\mathrm{CH}_{2} \mathrm{OHCOO}\right)_{2}\right)^{+} \frac{k_{\mathrm{i}}}{\mathrm{Slow}} \\
\left(\mathrm{Mn}(\mathrm{M})\left(\mathrm{CH}_{2} \mathrm{OHCOO}\right)\right)^{2+}+ \\
(\mathrm{Mn}(\mathrm{OH}))^{+}+\mathrm{R}-\dot{\mathrm{M}}
\end{aligned}
$$

Propagation:

$$
\begin{aligned}
& \mathrm{R}-\dot{\mathrm{M}}+\mathrm{M} \stackrel{k_{\mathrm{p}}}{\longrightarrow} \mathrm{R}-\dot{\mathrm{M}}_{2} \\
& \mathrm{R}-\dot{\mathrm{M}}_{n-1}+\mathrm{M} \stackrel{k_{\mathrm{p}}}{\longrightarrow} \mathrm{R}-\dot{\mathrm{M}}_{n}
\end{aligned}
$$

Termination:

$$
\dot{\mathrm{M}}_{n}+\dot{\mathrm{M}}_{m} \stackrel{k_{\mathrm{t}}}{\longrightarrow} \mathrm{M}_{n+m}
$$

\section{Rate Dependence on Potassium Permanganate Concentration}

The effect of permanganate concentration

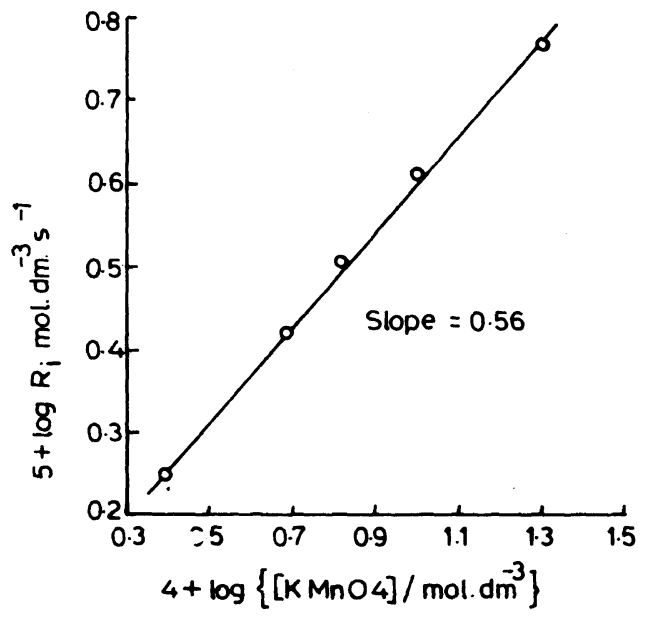

Figure 1. Double logarithmic plot of initial rate of polymerization $\left(R_{\mathrm{i}}\right) v s$. initial concentration of permanganate (temp, $35^{\circ} \mathrm{C}, \mathrm{pH}=3.11$ ). [Methacrylamide] = $2.0 \times 10^{-1} \mathrm{~mol} \mathrm{dm}^{-1} ; \quad$ [Glycollic acid] $=4.0 \times 10^{-3}$ $\mathrm{mol} \mathrm{dm} \mathrm{d}^{-3}$.

variation has been studied at constant concentrations of the monomer and activator. It is apparent from the results (Table I) that the initial rate of polymerization increases on increasing the concentration of permanganate from $(2.5-20.0) \times 10^{-4} \mathrm{~mol} \mathrm{dm}^{-3}$. However, the maximum conversion increases on increasing the concentration of permanganate but the rate at maximum conversion at higher concentrations of permanganate is comparatively slow. Since the initial rate of polymerization $\left(R_{\mathrm{i}}\right)$ increases with an increase in the permanganate concentration, the possibility of $\mathrm{Mn}$ (III) ion participation in the termination process is thus ruled out. The order of reaction with respect to the initiator as calculated from double logarithmic plot (Figure 1) is one half, which clearly indicates that the termination of growing polymer chains takes place through biomolecular interactions of immature polymeric chains. The viscometric average molecular weight (Table I) varies inversely to the square root concentration of permanganate and is in accordance with the results of other workers. ${ }^{7}$ At still higher concentrations $\left(>2.0 \times 10^{-3}\right.$ 
Table I. Effects of potassium permanganate concentration variation on the rate of polymerization $^{\mathrm{a}}\left(\mathrm{temp}, 35^{\circ} \mathrm{C} ; \mathrm{pH}=3.11\right.$ )

\begin{tabular}{|c|c|c|c|c|c|c|c|c|}
\hline \multirow{2}{*}{$\begin{array}{c}{\left[\mathrm{KMnO}_{4}\right] \times 10^{4}} \\
\mathrm{~mol} \mathrm{dm}^{-3}\end{array}$} & \multicolumn{7}{|c|}{$\%$ conversion at different intervals of time $/ \mathrm{min}$} & \multirow{2}{*}{$\bar{M}_{v} \times 10^{-3}$} \\
\hline & 2 & 5 & 10 & 20 & 50 & 80 & 130 & \\
\hline 2.50 & 1.08 & 2.68 & 5.32 & 11.02 & 23.00 & 26.88 & 29.62 & 31.5 \\
\hline 5.00 & 1.58 & 3.92 & 8.05 & 16.50 & 29.00 & 31.50 & 33.76 & 21.9 \\
\hline 6.67 & 1.92 & 4.88 & 11.25 & 19.38 & 31.00 & 33.25 & 34.25 & 17.8 \\
\hline 10.00 & 2.44 & 6.38 & 19.25 & 26.50 & 33.50 & 36.00 & 39.00 & 13.9 \\
\hline 20.00 & 3.56 & 13.75 & 23.12 & $29 ! 00$ & 34.88 & 37.00 & 37.75 & 8.5 \\
\hline
\end{tabular}

${ }^{\mathrm{a}}[$ Methacrylamide $]=2.0 \times 10^{-1} \mathrm{~mol} \mathrm{dm}^{-3} ;$ [Glycollic acid $]=4.0 \times 10^{-3} \mathrm{~mol} \mathrm{dm}^{-3}$.

Table II. Change in $\mathrm{pH}$ and $\bar{M}_{v}$ on varying the concentration of glycollic acid ${ }^{\mathrm{a}}\left(\mathrm{temp}, 35^{\circ} \mathrm{C}\right)$

\begin{tabular}{clrrrr}
\hline [Glycollic acid] $\times 10^{3} \mathrm{~mol} \mathrm{dm}^{-3}$ & $=$ & 3.33 & 10.00 & 33.30 & 50.00 \\
$\bar{M}_{v} \times 10^{-3}$ & $=$ & 24.49 & 25.08 & 21.30 & 25.47 \\
$\mathrm{pH}$ & $=$ & 3.15 & 2.91 & 2.65 & 2.56 \\
\hline
\end{tabular}

${ }^{a}[$ Methacrylamide $]=2.0 \times 10^{-1} \mathrm{~mol} \mathrm{dm}^{-3} ;\left[\mathrm{KMnO}_{4}\right]=4.0 \times 10^{-4} \mathrm{~mol} \mathrm{dm}^{-3}$.

mol dm ${ }^{-3}$ ) of permanganate the $R_{\mathrm{i}}$ and maximum conversion decrease substantially as reported by other workers. ${ }^{1,2}$

\section{Rate Dependence on Glycollic Acid Concen- tration}

The results given in Figure 2 show that $R_{\mathrm{i}}$ is more or less independent of the glycollic acid concentration in the range from $(2.33-50.0)$ $\times 10^{-3} \mathrm{moldm}^{-3}$ and the maximum conversion decreases appreciably on increasing the concentration of glycollic acid. Therefore, the initial nature of the reaction can be explained as due to side reactions ${ }^{8}$ betwen hydrogen ions (furnished by glycollic acid) (Table II) and $\mathrm{Mn}(\mathrm{IV})$ ions which decrease the overall concentration of active $\mathrm{Mn}$ (III) ions in the system. Hence in the initial part of reaction there exists a balance between the Mn(III) formation step and direct reduction on $\mathrm{Mn}(\mathrm{IV})$ by this side reaction. The viscometric average molecular weight remains constant (Table II) on varying the concentration of glycollic acid, which provides other support to assume that the initial rate of polymerization is independent of the concen-

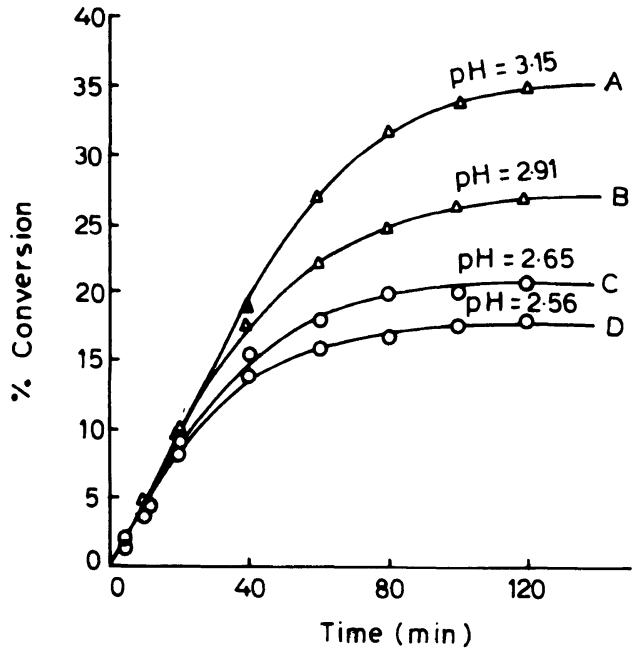

Figure 2. Effects of glycollic acid concentration variation on the rate of polymerization (temp, $35^{\circ} \mathrm{C}$ ). $\left[\right.$ Methacrylamide] $=2.0 \times 10^{-1} \mathrm{~mol} \mathrm{dm}^{-3} ; \quad\left[\mathrm{KMnO}_{4}\right]=$ $4.0 \times 10^{-4} \mathrm{~mol} \mathrm{dm}^{-3}$; [Glycollic acid] $(\mathrm{A})=3.33 \times 10^{-3}$ $\mathrm{mol} \mathrm{dm}{ }^{-3} ; \quad(B)=10.0 \times 10^{-3} \mathrm{~mol} \mathrm{dm}^{-3} ; \quad(C)=33.30 \times$ $10^{-3} \mathrm{moldm}^{-3} ;$ (D) $=50.0 \times 10^{-3} \mathrm{~mol} \mathrm{dm}^{-3}$.

tration of glycollic acid.

Rate Dependence on Methacrylamide Concentration

On varying the concentration of methac- 
Table III. Effects of methacrylamide concentration variation on the rate of polymerization ${ }^{\mathrm{a}}$ (temp, $35^{\circ} \mathrm{C} ; \mathrm{pH}=3.07$ )

\begin{tabular}{|c|c|c|c|c|c|c|c|c|c|}
\hline \multirow{2}{*}{$\begin{array}{c}{[\text { Methacrylamide }]} \\
\times 10^{2} \text { mol dm }^{-3}\end{array}$} & \multicolumn{8}{|c|}{$\%$ conversion at different intervals of time $/ \mathrm{min}$} & \multirow{2}{*}{$\bar{M}_{v} \times 10^{-3}$} \\
\hline & 2 & 5 & 10 & 15 & 25 & 45 & 85 & 125 & \\
\hline 5.00 & 0.57 & 1.42 & 2.95 & 4.45 & 12.00 & 20.12 & 24.88 & 26.25 & 1.22 \\
\hline 8.33 & 0.98 & 2.25 & 4.58 & 7.10 & 15.00 & 23.50 & 29.60 & 30.90 & 3.25 \\
\hline 12.50 & 1.49 & 3.70 & 7.12 & 11.16 & 20.00 & 27.40 & 32.50 & 34.10 & 6.52 \\
\hline 25.00 & 2.92 & 7.02 & 14.10 & 21.80 & 27.00 & 32.40 & 37.40 & 39.00 & 21.75 \\
\hline 40.00 & 3.87 & 9.50 & 20.38 & 27.75 & 30.62 & 34.75 & 37.75 & 39.02 & 29.75 \\
\hline
\end{tabular}

${ }^{\mathrm{a}}\left[\mathrm{KMnO}_{4}\right]=5.0 \times 10^{-4} \mathrm{~mol} \mathrm{dm}{ }^{-3} ;[$ Glycollic acid $]=5.0 \times 10^{-3} \mathrm{~mol} \mathrm{dm}^{-3}$.

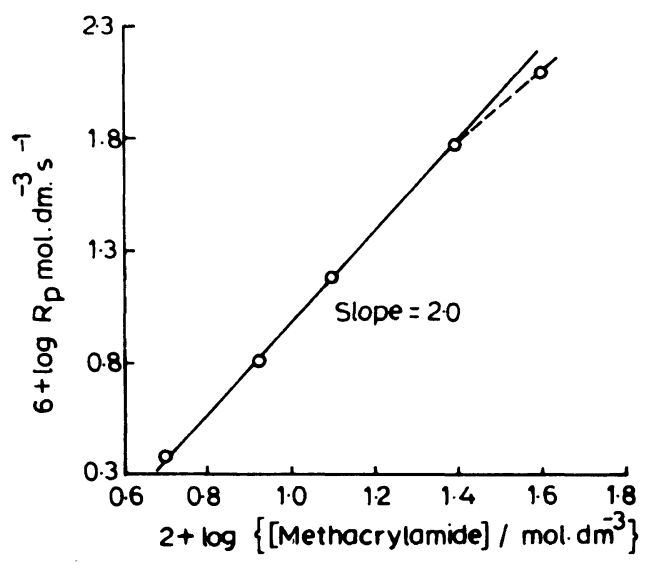

Figure 3. Double logarithmic plot of rate of propagation $R_{\mathrm{p}} v s$. initial concentration of methacrylamide (temp, $35^{\circ} \mathrm{C}, \mathrm{pH}=3.07$ ). $\left[\mathrm{KMnO}_{4}\right]=5.0 \times 10^{-4}$ mol dm ${ }^{-3} ;$ [Glycollic acid $]=5.0 \times 10^{-3} \mathrm{~mol} \mathrm{dm}^{-3}$.

rylamide from $5.0-25.0 \times 10^{-2} \mathrm{~mol} \mathrm{dm}^{-3}$ the rate of propagation $\left(R_{\mathrm{p}}\right)$ increased proportionally (Figure 3 ) but the maximum conversion remained more or less constant at higher concentrations (Table III). The order of reaction with respect to methacrylamide has been determined by making a log-log plot, (Figure 3) between the initial concentration of methacrylamide $v s$. the rate of propagation, which has been found to be two. The viscometric average molecular weight increased on increasing the concentration of methacrylamide from $(5.0-25.0) \times 10^{-2} \mathrm{~mol} \mathrm{dm}^{-3}$ (Table III) but showed deviation from linearity at higher concentrations which can be ex- plained by assuming that at higher concentrations of monomer the excess molecules of methacrylamide act as a solvent ${ }^{9}$ to facilitate the mobility of growing chain radicals to interact with each other. Hence the termination of premature growing chains is prevalent.

\section{Rate Dependence on Temperature}

The rate of polymerization of methacrylamide has been studied by varying the temperature from 25 to $50^{\circ} \mathrm{C}$ (Table IV) and the overall energy of activation $\Delta E$ has been calculated from the Arrhenius plot (Figure 4) which has been found to be $73 \pm 2 \mathrm{~kJ} \mathrm{~mol}^{-1}$ The results (Table IV) show that $R_{\mathrm{i}}$ and maximum conversion increase up to $45^{\circ} \mathrm{C}$, but at still higher temperatures, the maximum conversion decreases. The viscometric average molecular weight decreased on increasing the temperature which may be due to the higher rate of biomolecular termination of growing chain radicals.

\section{Effect of Sulfuric Acid}

The rate of polymerization of methacrylamide has been studied by varying the concentration of sulfuric acid from $2.5 \times 10^{-4}$ $1.0 \times 10^{-2} \mathrm{~mol} \mathrm{dm}^{-3}$ whereas the $\mathrm{pH}$ varied from 2.99 to 1.97 (Figure 5). The results showed that the initial rate of polymerization increased in the concentration range from $(2.5-7.5) \times 10^{-4} \mathrm{moldm}^{-3}$ of sulfuric acid ( $\mathrm{pH}$ varies from 2.99 to 2.82 ) but the max- 
Polymerization of Methacrylamide by Redox System

Table IV. Effects of temperature on the rate of polymerization ${ }^{\mathrm{a}}(\mathrm{pH}=3.11)$

\begin{tabular}{|c|c|c|c|c|c|c|c|c|c|}
\hline \multirow{2}{*}{$\frac{\text { Temperature }}{{ }^{\circ} \mathrm{C}}$} & \multicolumn{8}{|c|}{$\%$ conversion at different intervals of time $/ \mathrm{min}$} & \multirow{2}{*}{$\bar{M}_{v} \times 10^{-3}$} \\
\hline & 2 & 5 & 10 & 20 & 30 & 50 & 80 & 130 & \\
\hline 25 & 0.52 & 1.26 & 2.40 & 4.88 & 7.70 & 15.40 & 23.50 & 26.75 & 47.17 \\
\hline 30 & 0.79 & 2.08 & 4.02 & 8.82 & 17.45 & 25.40 & 29.42 & 30.25 & 37.27 \\
\hline 35 & 1.23 & 3.35 & 11.25 & 21.15 & 25.00 & 29.05 & 31.35 & 33.40 & 29.24 \\
\hline 45 & 3.08 & 8.05 & 18.15 & 28.75 & 34.25 & 39.20 & 43.50 & 45.50 & 15.95 \\
\hline 50 & 4.92 & 15.75 & 27.80 & 33.25 & 36.50 & 39.75 & 41.20 & 42.45 & 10.64 \\
\hline
\end{tabular}

${ }^{\mathrm{a}}[$ Methacrylamide $]=2.0 \times 10^{-1} \mathrm{~mol} \mathrm{dm}^{-3} ;\left[\mathrm{KMnO}_{4}\right]=5.0 \times 10^{-4} \mathrm{~mol} \mathrm{dm}^{-3} ;[$ Glycollic acid $]=4.0 \times 10^{-3} \mathrm{~mol} \mathrm{dm}^{-3}$.

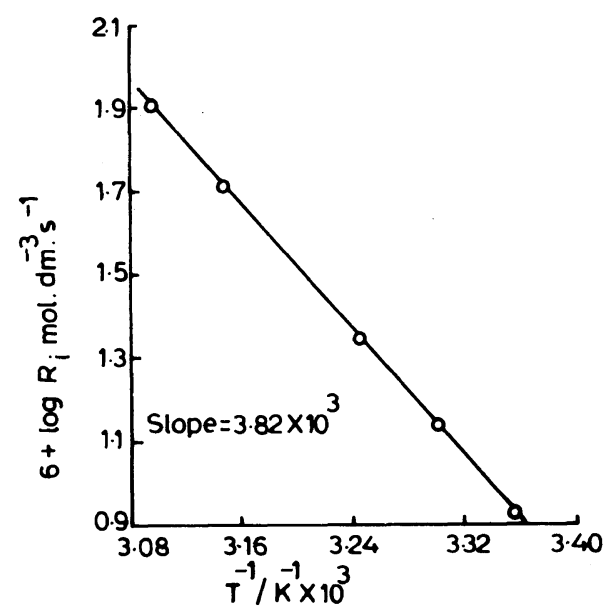

Figure 4. Arrhenius plot of initial rate of polymerization $\left(R_{\mathrm{i}}\right)$ vs. reciprocal of absolute temperature $(\mathrm{pH}=$ 3.11). [Methacrylamide] $=2.0 \times 10^{-1} \mathrm{~mol} \mathrm{dm}^{-3}$; $\left[\mathrm{KMnO}_{4}\right]=5.0 \times 10^{-4} \mathrm{~mol} \mathrm{dm}^{-3} ; \quad$ [Glycollic acid] = $4.0 \times 10^{-3} \mathrm{~mol} \mathrm{dm}^{-3}$.

imum conversion showed a decreasing trend on increasing the concentration of sulfuric acid. The increase in the initial rate with an increase in the sulfuric acid concentration from $(2.5-7.5) \times 10^{-4} \mathrm{moldm}^{-3}$ can be explained by the formation of an additional redox pair ${ }^{10}$ between $\mathrm{Mn}(\mathrm{IV})$ and $\mathrm{SO}_{4}^{2-}$ ions which produce $\mathrm{SO}_{4}^{-}$radicals in the system, and hence the initial rate of polymerization increases.

$$
\begin{aligned}
\mathrm{Mn}(\mathrm{IV})+2 \mathrm{SO}_{4}^{2-}+ & 4 \mathrm{H}^{+} \longrightarrow \\
& \mathrm{Mn}(\mathrm{II})+2 \mathrm{SO}_{4}^{-}+2 \mathrm{H}_{2} \mathrm{O}
\end{aligned}
$$

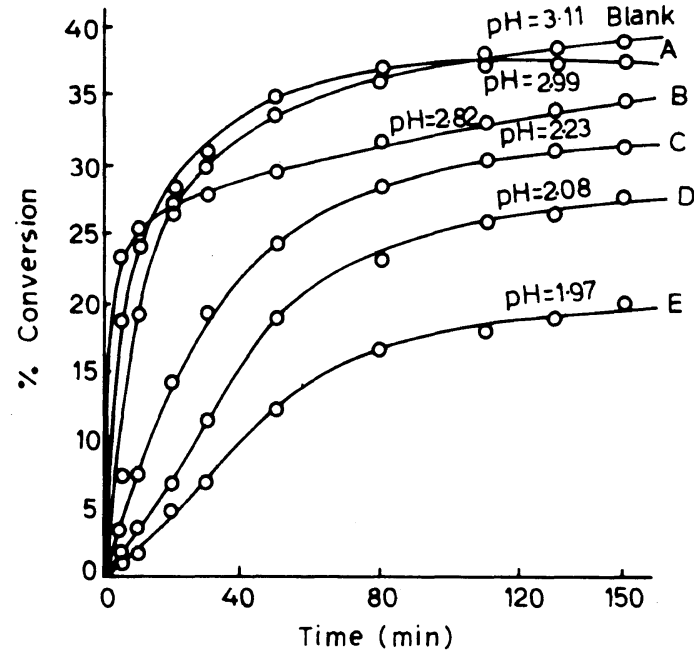

Figure 5. Effects of sulfuric acid (temp, $35^{\circ} \mathrm{C}$ ). $[$ Methacrylamide $]=2.0 \times 10^{-1} \mathrm{moldm}^{-3} ;\left[\mathrm{KMnO}_{4}\right]=$ $10.0 \times 10^{-4} \mathrm{~mol} \mathrm{dm}^{-3} ;$ [Glycollic acid] $=4.0 \times 10^{-3}$ mol dm ${ }^{-3}$; [Sulfuric acid] $(A)=2.5 \times 10^{-4} \mathrm{~mol} \mathrm{dm}^{-3}$; (B) $=7.5 \times 10^{-4} \mathrm{~mol} \mathrm{dm}^{-3} ;$ (C) $=5.0 \times 10^{-3} \mathrm{~mol} \mathrm{dm}^{-3}$; (D) $=7.5 \times 10^{-3} \mathrm{~mol} \mathrm{dm}^{-3}$; (E) $=1.0 \times 10^{-2} \mathrm{~mol} \mathrm{dm}^{-3}$.

But at a higher concentration of sulfuric acid, i.e., $>7.5 \times 10^{-4} \mathrm{~mol} \mathrm{dm}^{-3}$ this reaction may be suppressed by the direct reduction of $\mathrm{Mn}(\mathrm{IV})$ ions into $\mathrm{Mn}(\mathrm{II})$ ions without forming $\mathrm{SO}_{4}^{-}$radicals. Therefore, the initial rate of polymerization and maximum conversion have been found to decrease.

Considering the above experimental results and proposed steps $1-9$, the rate of propagation $\left(R_{\mathrm{p}}\right)$ can be given as

$$
R_{\mathrm{p}}=k_{\mathrm{p}}\left\{\frac{k_{1} k_{5}}{2 k_{\mathrm{t}}}\right\}^{1 / 2}[\mathrm{M}]^{2}\left[\mathrm{KMnO}_{4}\right]_{0}^{1 / 2}
$$


where,

$$
k_{5}=k_{\mathrm{h}} k_{3} k_{4}\left[\mathrm{H}_{2} \mathrm{O}\right]^{2}
$$

The derived rate expression 10 is in conformity with the experimental results, i.e., the rate of polymerization is square dependent to the concentration of methacrylamide and independent of glycollic acid concentration. The order with respect to permanganate concentration is found to be half. Hence the validity of the proposed steps $1-9$ and the rate expression 10 has been proved.

Acknowledgement. The authors are thankful to C.S.I.R. New Delhi for providing financial assistance.

\section{REFERENCES}

1. G. S. Misra and U. D. N. Bajpai, J. Macromol. Sci.Chem., A, 13, 1135 (1979).

2. G. S. Misra and J. J. Rebellow, Makromol. Chem., 175, 3117 (1974).

3. K. C. Gupta and K. Behari, Colloid Polym. Sci, 262, 677 (1984).

4. S. K. Chatterjee, E. Prokopova, and M. Bohdanecky, Eur. Polym. J., 14, 665 (1978).

5. D. R. Man and F. C. Tompkin, Trans. Faraday Soc., 37, 201 (1941).

6. A. Gopalan, S. Paulrajan, K. Venkatarao, and M. R. Subbaratnam; Eur. Polym. J., 19, 817 (1983).

7. G. S. Whitby, M. D. Cross, J. R. Miller, and A. J. Costanza, J. Polym. Sci., 16, 549 (1955).

8. K. Behari, K. C. Gupta, and M. Verma, Angew. Makromol. Chem., 130, 67 (1985).

9. R. G. W. Norrish and R. R. Smith, Nature (London), 150, 336 (1942).

10. S. R. Palit and R. S. Konar, J. Polym. Sci, 57, 609 (1962). 